\title{
Violence against children: the routine of the professionals in the primary health care
}

\author{
Violência contra criança: cotidiano de profissionais na atenção primária à saúde
}

Josiane Nunes Maia ${ }^{1}$, Rosângela Aparecida Pimenta Ferrari ${ }^{1}$, Flávia Lopes Gabani ${ }^{1}$, Mauren Teresa Grubisich Mendes Tacla ${ }^{1}$, Taísa Bastos dos Reis ${ }^{1}$, Mariana Lucas Camilo Fernandes ${ }^{1}$

Objective: to grasp the every day of the professionals in the primary care health service in the cases of violence against children. Methods: this is a qualitative study conducted in nine Basic Health Units. For analysis of the material, the Content Analysis was used, specifically thematic analysis. Results: the speeches of professionals allowed the construction of two themes: Professionals facing cases of violence against children: between reason and emotion; Integration of health services, education, justice, and community: opportunities and challenges for addressing violence against children. Conclusion: the facilities to cope with the violence against children were much smaller than the difficulties, especially those related to absence family protocols and lack of in-service training.

Descriptors: Violence; Child; Primary Health Care; Health Personnel; Pediatric Nursing.

Objetivo: apreender o cotidiano de profissionais do serviço de atenção primária de saúde frente aos casos de violência contra a criança. Métodos: estudo qualitativo, realizado em nove Unidades Básicas de Saúde. Para análise do material, utilizou-se Análise de Conteúdo, especificamente Análise Temática. Resultados: os discursos dos profissionais possibilitaram a construção de dois temas: Os profissionais frente aos casos de violência contra criança: entre a razão e a emoção; Integração entre serviços de saúde, educação, justiça e comunidade: possibilidades e desafios para o enfrentamento da violência contra a criança. Conclusão: as facilidades para o enfrentamento da violência contra criança foram muito menores do que as dificuldades, principalmente as relacionadas à família, ausência de protocolos e carência de treinamento em serviço.

Descritores: Violência; Criança; Atenção Primária à Saúde; Pessoal de Saúde; Enfermagem Pediátrica.

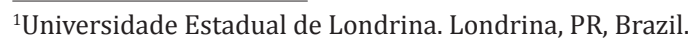




\section{Introduction}

Despite the rights and the protection ensured by the Children and Adolescents Statute since 1990, it is still common and alarming the frequency of cases of violence against children, which includes the age from birth to 12 years old, as well as the adolescents between 12 and 18 years old ${ }^{(1)}$. By law, the children and adolescents have the physical, mental, moral, spiritual and social right, freedom and dignity, not suffering any form of neglect, violence, exploitation, cruelty and oppression ${ }^{(1)}$. Besides being a painful reality, the violence against children brings the short, medium and long-term damage, both physical and psychosocial that are reflected in adulthood ${ }^{(2)}$. In adolescence, the increasing morbidity and mortality observed in the last two decades is related, for the most part, with the consequences of violence and injuries, disabilities, homicide, but also with contamination by diseases resulting from poor living conditions, suicides, and $\operatorname{accidents}^{(3)}$.

Natural deaths caused by diseases are not being the leading cause of death among children and adolescents, decreasing $77.1 \%$ between 1980 and 2010. Deaths by external causes (homicides, violence, accidents, falls, injuries and diseases) are growing surprisingly since 1980 when the number still amounted to $6.7 \%$ and in 2010 rose to $26.5 \%$ and tends to progress, which justifies the concern about the rapid growth of these indices ${ }^{(4)}$. Every day in Brazil, there are 129 cases of psychological and physical violence recorded on average, including sexual, and neglect against children and adolescents. This means that every hour, there are five cases of violence against girls and boys. This reality can be even more serious considering that many of these crimes are never reported $^{(5)}$.

The main types of abuse against children and adolescents are neglect and abandonment: omissions of parents or other guardians (including insti- tutional), when they fail to provide basic necessities for their physical, emotional and social development; psychological abuse: any form of rejection, depreciation, discrimination, disrespect, exaggerated charges, humiliating punishments and the use of children or adolescents to meet the psychological needs of adults; Sexual abuse: any act or sexual game, heterosexual or homosexual relationship, whose perpetrator is in the psychosexual development stage earlier than the victim, whose sexually intention is stimulate it or use it for sexual satisfaction ${ }^{(6)}$.

Violence against children and adolescents is a multi-factorial problem, which consists of a variety of variables and affecting all socioeconomic and cultural levels of the society. These reasons need the intervention of a multidisciplinary and interdisciplinary team ${ }^{(2)}$, and the action becomes more effective when promoted by a set of institutions acting in a coordinated manner ${ }^{(7)}$. On the other hand, although it is mandatory to fill the suspected Notification Form or confirmation of maltreatment against children and adolescents and their referral to the Guardianship Council by professionals and health institutions that meet the National Health System, underreporting is a present reality, hindering the resolution of cases ${ }^{(6)}$.

The notification of violence cases and the assistance provided to victims is restricted by many factors, such as cultural, social, limited infrastructure and human resources, hindering to identify the cases $^{(8)}$. The act of notifying start a process that aims to stop the attitudes and violent behavior in the family and any aggressor ${ }^{(7)}$. This fact justifies the need for investment in training of professionals who deal with violence against children and adolescents and their sensitization to detect not only extreme cases but mostly the veiled $\operatorname{cases}^{(8)}$.

Regarding the human resources, this study aimed to grasp the professional every day in the primary care health service in the cases of violence against children. 


\section{Methods}

It is a qualitative study conducted from August to September 2012, in Londrina, PR, Brazil.

The municipality offers reference and counter service for child care to the population, such as community mental health services; an Emergency Care Children that works 24 hours in the central region; three Guardianship Councils located in the north, center and south area, with the support of the Childhood and Adolescence and Social Action; Eye on the Future project - Department of Social Work and Social Psychology at the State University of Londrina; Specialized Reference Center for Social Assistance, old Sentinel program; Rosa Viva Project - Municipal Maternity of Londrina; internal committee of child advocacy and adolescent victims of abuse - University Hospital of Londrina State University and; Court and prosecution of the Children and Youth Court.

The health system consists of 52 basic health units distributed in the six areas of the city (center, north, south, east, west and rural area) and the northern region with the largest urban concentration of population and number of establishment (9) and then the south (7). The study participants were professionals from nine units in the northern region who performed direct assistance to children under 12 years old as established in the Child and Adolescent Statute $^{(1)}$ and agreed to participate: nurses, pediatricians, nursing technicians/assistants, dentist, dental assistant and community health agents. Medical care for children up to 12 years old in this service is restricted to the pediatric area, an object of this study, so the overall clinical specialty and gynecology and obstetrics were excluded.

For data collection, the researchers scheduled a meeting with the coordinator of each health unit to present the research objectives and the form of research. After the release of the presence of researchers to address the unit staff, a semi-structured instrument with previously validated questions was used, so that each one individually fills it in due time during the work period. After filling it, the professionals deposited it into a sealed box to take it by the researcher in previously scheduled date with the team.

Professionals wrote about their everyday life, answering the following questions: Describe the facilities to deal with violence against children in the health unit; describe the difficulties to deal with violence against children in the health unit; explain what are your perspectives to address the cases of violence against children in the health unit.

The methodological reference of Content Analysis was used. Specifically, the thematic analysis ${ }^{(9)}$, and the following steps were fulfilled: preanalysis, material exploration and processing of the results. The selection of content emerged through a process of comparison, grouping the units of meaning for similarities and differences that generated the categories of analysis ${ }^{(9)}$. For confidentiality of the individuals, they were identified by the professional category, followed by an Arabic number, according to the interview order, as follows: Nurse ( $\left.\mathrm{N} \mathrm{n}^{\circ}\right)$ Pediatrician ( $\mathrm{P} \mathrm{n}^{\mathrm{o}}$ ), Nursing Technician/Assistant $\left(\mathrm{NTA}^{\circ}{ }^{\circ}\right)$ Dentist $\left(\mathrm{D}^{\mathrm{o}}{ }^{\circ}\right)$, Dental Assistant (DA $\mathrm{n}^{\circ}$ ) and

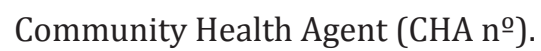

The study complied with the formal requirements contained in the national and international regulatory standards for research involving human beings.

\section{Results}

From 180 professionals in nine health units, there were six professional categories in the research: 66 community health agents, 54 nursing technician/ assistants, 26 nurses, 2 pediatricians, 22 dental assistant and 10 dentists. The Community Health Agents, nursing technician/assistants and nurses were the most attending these cases, most commonly by neglect and abandonment (43.3\%), psychological abuse $(22.8 \%)$, physical abuse $(20.0 \%)$ and sexual abuse $(16.1 \%)$, usually more than one type of one assistance. 
From the speeches of the professionals from the different categories, it was possible to see two themes: Professionals facing cases of violence against children: between reason and emotion and Integration between health services, education, justice, and community: opportunities and challenges confronting the violence against children.

\section{Professionals facing cases of violence against children: between reason and emotion}

This topic deals with the operation of cases of child abuse in professional work routine in health facilities. Few of them (18) reported facilities in meeting the victims. Among them, there was the availability of pediatric agenda, enabling an immediate response. Also child care and immunization programs, and the proximity of the team to the coverage area of the community: To meet a large number of children per month, to meet many families of the Basic Health Unit region to work a long time on the place some patients and families go in the dental clinic, perhaps to return frequently to the clinic (D 1). Due to the direct care, child care, evaluation, pediatric, vaccines and other, it is noticed direct signals connected to carelessness, negligence and even sexual assault (NTA 5). Because being a health agent and known in the area where I work, I always see the problem, going in the house and seeing the real situation of the family (CHA 9).

Another aspect facilitating to address violence against children was noted in the speeches of professionals to count on a multidisciplinary team at the facility and have a referral service in the city: Having the social worker and house psychologist in the Basic Health Unit, the family approach and contact with other services (N 1). Referral to the Child Emergency Department fit for a pediatrician in the Basic Health Unit (NTA 5).

If on the one hand, the professionals consider that the proximity to the community, calendar of availability and multi-professional team favors addressing violence, on the other hand, some of them pointed out some difficulties, such as fear of being a victim of the aggressor, the way to approach the child abused and the family. These difficulties explain the discourse with negative experiences in daily work, feeling of helplessness by cases due to the socioeconomic instability of families and victims: There are many, from the appropriate way to address the problem with relatives or guardians especially in suspected cases of sexual abuse, to the decision-making on how to act. I went through a situation like this in public, and I never forget what I felt: embarrassment, anger, insecurity, powerlessness, eager to act without knowing how (NTA 6). Fear of interfering in the personal lives of families and "reprisal" for it (by parents) (D 9). The greatest difficulty is the feeling of helplessness that accompanies the situation (NTA 11). It is difficult to approach because often the perpetrators are family members, protection services to these children are very precarious, the delay and the fact of putting his life at risk (CHA 11).

Besides the fear and difficulty of professionals to address the cases, there were evidenced-personal difficulties in coping with the situation by mobilizing feeling with much suffering: For me, violence against children is an issue that shakes me enough (DA 2). I am touched with the thought always returning to the case, and especially when I associate it with any of my three children. I do not know if it is good to be more affective or be more serious not to sensitize the child (D 5) further. It is difficult to address this situation; it is not a structured family, but it is not easy to deal with feelings (N 14). Especially emotional because when all children are shaken. I am a mother, as a child has a future, joy, naive, innocence and unfortunately this will cause a trauma for life (NTA 16).

With regard to combating violence against children, professionals reported that the family context complicates the management and resolution of cases as often faced with the omission of relatives and neighbors, as well as the dependence of the abuser of the child can be a paternal or maternal figure: Identifying the attackers, since most children, victims of violence, are threatened and therefore hide the aggression and the aggressors. As the children normally require the presence of a parent or guardian to be treated at the Basic Health Unit, it makes it much harder to research because the child feels embarrassed to talk about violence (DA 10). The family 
does not provide sufficient data, denying the incident (NTA 18). The difficulties are many, for the family omission of reasons, neighbors, it is a delicate and complicated issue to be addressed, especially in community liaison function because we have a direct contact with the family, then you must use velvet glove, trying work with family and unit staff (CHA 38).

Although the family context hinders the confrontation of cases of child abuse by professionals, some statements indicated the need to understand the family context and the child's behavior that when changed, it can provide input to identify and intervene as soon as possible, stopping the perpetuation of violence: Understanding the family context and work on the causes of the family problems ... (D 1). To take more attention to children (NTA 2). Checking the treatment and emotional state of the child, behavior changes and analyzing the honesty and reality of the situation (CHA 3).

Integration between health services, education, justice and community: opportunities and challenges confronting the violence against children

This topic refers to the coping with the abused child because it is not restricted only to detect, but the identification of risk, integrated work in institutions networks providing services to this age group, such as health, education and international justice related to the community.

The speeches of professionals pointed out that cases of violence against children should be protected by strict, effective and efficient laws, so that the perpetrators are denounced and punished, as well as network integrated policy to investigate cases and follow-up to interruption of violent acts supporting victims economically dependent on offenders: $A$ strict law, which should obviously be fulfilled (P 1). Make clear to aggressors and abusers that they will certainly be caught and punished (NTA 8). There is a broader policy, where cases of allegations are effectively investigated and where there are doubts, the posterior approach is performed periodically, even without further complaint (D 3). A more structured and organized network to meet these types of cases $(\mathrm{N}$ 12). Structuring of households with health measures and education to victims in most cases both the mother and the child suffers violence depend on economical aggressor (CHA 5).

In addition to the judicial intervention, some speeches of professionals also pointed to health actions with interventions during prenatal care, guiding the importance of the bond with the child and preventing unwanted pregnancies as a way to prevent violence. On the other hand, the team must promote quality of life, interact with parents and provide specialized treatment. Training for future mothers (AD 1). Improving the quality of life; study opportunities; education for parents; work to avoid an unwanted pregnancy (N 3). There is a link to the child with the parents; we need to "work" the parents treating their wounds (N 14).

Other forms of health actions are the preventive work of violent acts in different ways, with children, adolescents, families and communities of the health facilities neighborhoods. This work with a multidisciplinary team through lectures, meetings, and awareness workshops encourage attitudes of peace and quality of life: Providing meeting and educational activities with the community along with a multidisciplinary team to help every citizen to know and understand better himself and others. Activities to combat stress, expand awareness and improve self-esteem; violence in our actions and attitudes is only a reflection of the inner imbalance and the way we are living (D 2). Actions that promote family unity, for example; speeches; information to people about the consequences of violence for the child and the abuser; rescue the family responsibility (DA 4). Educational activities with students from public, private schools and in day care centers and academies (NAT 15).

Although professionals have identified different forms of interventions in social, health, justice, education and community, they reported that they are not prepared to deal with violence against children stating, in the following discourse, that managers should provide in-service training, and implement protocol in primary health care network with availability of reference and counter-reference services for 
care cases: I am not trained to the problem how to approach the resident with the specific subject (CHA 9). I think the lack of training to deal with this situation (DA 2). It is necessary a discussion of a protocol on the Basic Health Unit with the entire team (N 7). A protocol with a detailed description of a flow of service (N 12). Lack of single protocol for all services involved, passing cases and have counter-reference of the tutelary council, staff trained to deal with cases (N 16).

In addition to local actions, professionals have pointed out that the State must assume its responsibilities so that the laws be fulfilled, subsidizing human and material resources for municipalities, implementing permanent education policy for health professionals involved in cases of violence against children and conducting educational campaigns to stop the cycle of violence in the society. Viabilization of resources for training and education for professionals (CHA 5). Enabling and encouraging campaigns and activities that expose and clarify the problem, providing support services to victims of violence (NTA 8). Public policy aimed at combating or preventing violence (campaigns, family therapy, among other important activities to reduce it) (DA 5).

\section{Discussion}

In this study, the limitations are related to one of the six regions of the municipality as well as the impossibility of obtaining all the professionals in the primary care network who experience their situations of violence against children in daily work. However, the participation of the subjects in the different categories, nurses, nursing technicians/assistants, community health agents, pediatrician, dentist and dental assistant, showed strengths and weaknesses in the service, routing and resolution of cases attended, given the complexity of family violence.

Regarding the care of child victims of violence by professionals in this study, the frequency was sporadic highlighting the neglect and abandonment, followed by psychological, physical and sexual abuse. In Brazil, there 17,900 violence cases reported among children under nine years old in 2011, with physical and more common among boys neglect and sexual and psychological violence among girls, the most prevalent cause were their parents at home ${ }^{(10)}$. In 2013 , these data prevailed ${ }^{(11)}$. In the family health units, about $50.0 \%$ to physical and sexual violence in the home, physical abuse of small and medium caused by burns and beatings were highlighted ${ }^{(12)}$.

Among the professionals that best suit these cases in this study, there were the community health agents, nursing technician/assistants and nurses, but the dental team and the pediatrician, each on their environmental performance, also providing assistance to victims of violence, and this variety was considered as one of the facilities for identification and monitoring of cases in the coverage area. Research showed that cases of violence were detected in different circumstances, doctors and nurses during the consultation, community health agents and nursing technicians by third parties and home visits $^{(13)}$. On the other hand, they feel more exposed to fear and reprisals ${ }^{(8)}$, as well as the child's family threats victim of abuse, not wanting this situation to be in the public domain ${ }^{(2)}$. Such situations have been identified as difficulties in this study.

It is possible to see that the fact that the victim is a child, makes the professional more vulnerable and sensitive to the situation because the association with their children is inevitable in these cases, the psychological balance is necessary, also referred by the subjects in this study. Feelings faced on cases of violence against children and contact with the abuser are reported as uncontrollable and range from shame and indignation to the aggressor anger and desire to take justice into their hands ${ }^{(14)}$. These feelings were also evident in the research with members of the Protection of Children and Youth Committee of the District of Setúbal, Portugal ${ }^{(15)}$.

The feeling of not being a qualified team to handle cases related to violence against children and 
adolescents, powerlessness, beyond the fears of facing the problem may hinder their visibility ${ }^{(10,16-17)}$. Fear of emotional involvement was present in more than half of the professionals, which can be synonymous with the absence of effective institutional support, causing inhibition of proactive steps in the resolution process $^{(7)}$. These feelings surfaced in the discourse of professionals who have experienced such situations were present in this study.

The difficulties of the professionals in the management of violence against children noted in other studies was due to the inefficiency of the health service, from the lack of training and lack of protocols to the absence of specific routines for performance ${ }^{(8,12)}$. The research found that $41.5 \%$ of the professionals who assisted cases of violence did not know where to refer the victim who has suffered mistreatment ${ }^{(7)}$. Such failures reflect negatively on the development of indicators, as well as the practice of prevention, intervention and law enforcement ${ }^{(16)}$.

Another difficulty confronting violence, as evidenced in the speeches of the subjects of this study was the behavior of the family. Research shows that the family may benefit or harm the investigation of the case by omitting and protect the abuser, which makes the situation even more revolting and unbearable for health professionals ${ }^{(14)}$. On the other hand, it is important to understand that social issues such as unemployment, lack of family planning, poverty, among other reasons, can trigger violence ${ }^{(10,18)}$. This situational analysis of the family environment was reported by some of the subjects of this study as one of the ways to stop the perpetuation of violence. In a study conducted in the United States to assess the benefits and harms of behavioral interventions and family counseling in cases of violence against children, the monitored systematically identified in the home environment, it was reduced to search for emergency services, hospitalization, abuse and neglect, and showed greater adherence to vaccination campaigns and childcare, unlike children treated at pediatric clinics $^{(15)}$.

The importance of the multidisciplinary work in combating violence is not limited to the health service, as in the speeches of the subjects of this study showing that goes beyond by institutional coordination and interaction between the different health sectors, education, social justice, etc. This relationship enables the implementation of the "Protection Network" also ensuring forwarding to instances of service and guarantee of rights ${ }^{(6,12)}$.

In Brazil, there is not yet fully effective in monitoring cases of violence against children, despite significant changes in this scenario, resulting from agreements with other agencies such as State and Federal Secretariats ${ }^{(10-11)}$. Early detection is critical to the effectiveness of intervention and social rehabilitation and moral of the child. However, not always violence is discovered quickly, requiring integrated instrument services to identify risk factors for its occurrence, and subsequent, monitoring it.

Although professionals working in primary health care have major responsibility for the care of child victims of abuse, there is not always fully aware of their role ${ }^{(8,16)}$. On the other hand, the subjects of this study pointed out that the institutions need to ensure the rights and working conditions for these professionals to perform their functions, such as provide and maintain professional support groups with different areas that deal with such cases, system reference and counter-reference team for social and psychological support of the child, family, and aggressor.

\section{Conclusion}

It was possible to observe in the discourse of professionals of different categories, that the difficulties to face the cases of violence against children in daily work in primary care overlap the facilities. 
Among the facilities, there were the actions in the health unit, due to the involvement of professionals in the resolution of cases of multi-form and proximity to the community. The difficulties were provided insufficient training and institutional support for the handling of cases of limited public policy to ensure the rights of children, as established by the Children and Adolescents Statute.

\section{Collaborations}

Maia JN contributed to the work design, data collection, analysis and writing of the article. Ferrari RAP contributed to the project design, guidance, writing and review. Reis TB and Fernandes MLC contributed to writing and review. Gabani FL and Tacla MTGM contributed to the relevant critical review of the content and final approval of the final version to be published.

\section{References}

1. Ministério da Justiça (BR). Presidência da República. Casa Civil. Lei no 8.069, de 13 de julho de 1990. Dispõe sobre o Estatuto da Criança e do Adolescente e dá outras providências. Brasília: Ministério da Justiça; 1990.

2. Ramos MLCO, Silva AL. Estudo sobre a violência doméstica contra a criança em unidades básicas de saúde do município de São Paulo-Brasil. Saúde Soc. 2011; 20(1):136-46.

3. Morais NA, Morais CA, Reis S, Koller SH. Promoção de saúde e adolescência: um exemplo de intervenção com adolescentes em situação de rua. Psicol Soc. 2010; 22(3):507-18.

4. Waiselfisz JJ. Mapa da violência 2012: crianças e adolescentes do Brasil. Centro Brasileiro de Estudos Latino-Americanos. Rio de Janeiro: Flacso Brasil; 2012.
5. Fundo das Nações Unidas para a Infância no Brasil. Nossas prioridades: Infância e adolescência no Brasil [Internet]. 2014 [citado 2016 abr. 11]. Disponível em: http://www.unicef.org/brazil/pt/ activities.html

6. Garbin CAS, Dias IA, Rovida TAS, Garbin AJÍ. Desafios do profıssional de saúde na notificação da violência: obrigatoriedade, efetivação e encaminhamento. Ciênc Saúde Coletiva. 2015; 20(6):1879-90.

7. Luna GLM, Ferreira RC, Vieira LJES. Notificação de maus tratos em crianças e adolescentes por profissionais de saúde da Equipe Saúde da Família. Ciênc Saúde Coletiva. 2010; 15(2):481-91.

8. Andrade EM, Nakamura E, Paula CS, Nascimento $\mathrm{R}$, Bordin IA, Martin D. A visão dos profissionais de saúde em relação à violência doméstica contra crianças e adolescentes: um estudo qualitativo. Saúde Soc. 2011; 20(1):147-55.

9. Bardin L. Análise de Conteúdo. São Paulo: Edições 70; 2011.

10. Rates SMM, Melo EM, Mascarenhas MDM, Malta DC. Violência infantil: uma análise das notificações compulsórias, Brasil 2011. Ciênc Saúde Coletiva. 2015; 20(3):655-65.

11. Nunes AJ, Sales MCV. Violência contra crianças no cenário brasileiro. Ciênc Saúde Coletiva. 2016; 21(3):871-80.

12. Leite JT, Beserra MA, Scatena L, Silva LMP, Ferriani MGC. Coping with domestic violence against children and adolescents from the perspective of primary care nurses. Rev Gaúcha Enferm. 2016; 37(2):1-7.

13. Woiski ROS, Rocha DLB. Cuidado de enfermagem à criança vítima de violência sexual atendida em unidade de emergência hospitalar. Esc Anna Nery. 2010; 14(1):143-50.

14. Oliveira P, Simões A. Maus tratos à infância: as referências dos técnicos das Comissões de Proteção de Crianças e Jovens (CPC)). Rev Port Enferm Saúde Mental. 2014; n.esp.1:82-9. 
15. Aragão AS, Ferriani MGC, Vendruscollo TS, Souza SL, Gomes R. Primary care nurses' approach to cases of violence against children. Rev Latino-Am Enfermagem. 2013; 21(n.esp.):172-9.

16. Bezerra KP, Monteiro AI. Violência intrafamiliar contra a criança: intervenção de enfermeiros da estratégia saúde da família. Rev Rene. 2012; 13(2):354-64.

17. Morais RLGL, Sales ZN, Rodrigues VP, Oliveira JS. Actions of protection for children and teenagers in situations of violence. J Res Fundam Care Online [Internet]. 2016 [cited 2016 Mar 16]; 8(2):447286. Available from: http://www.seer.unirio. $\mathrm{br} /$ index.php/cuidadofundamental/article/ view/4688/pdf_1902
18. Nelson HD, Selph S, Bougatsos C, Blazina I. Behavioral Interventions and Counseling to Prevent Child Abuse and Neglect: Systematic Review to Update the U.S. Preventive Services Task Force Recommendation [Internet]. 2013 [cited 2016 Mar 16]. Available from: http://www. ncbi.nlm.nih.gov/pubmedhealth/PMH0052380/ pdf/PubMedHealth_PMH0052380.pdf 